\title{
Adherence to a standard operating procedure for patients with acute cervical spine dislocations: review of a tertiary, referral, academic hospital in South Africa
}

\author{
Goud DD Ayik, ${ }^{1 *}$ Takura DM Mukabeta, ${ }^{1}$ George Nyandoro, ${ }^{2}$ Charles Osborne, ${ }^{3}$ Nicholas A Kruger ${ }^{1}$ \\ 1 Division of Orthopaedic Surgery, University of Cape Town, Cape Town, South Africa \\ 2 Department of Community Medicine, College of Health Sciences, University of Zimbabwe, Zimbabwe \\ 3 NHS Lothian Edinburgh Royal Infirmary, University of Aberdeen, Edinburgh, Scotland \\ *Corresponding author: gooddeng_75@yahoo.com
}

Citation: Ayik GDD, Mukabeta TDM, Nyandoro G, Osborne C, Kruger NA. Adherence to a standard operating procedure for patients with acute cervical spine dislocations: review of a tertiary, referral, academic hospital in South Africa. SA Orthop J 2021;20(2):81-87. http://dx.doi. org/10.17159/2309-8309/2021/ v20n2a3

Editor: Dr Johan Davis, Stellenbosch University, Cape Town, South Africa

Received: February 2019

Accepted: June 2020

Published: May 2021

Copyright: @ 2021 Ayik GDD. This is an open-access article distributed under the terms of the Creative Commons Attribution Licence, which permits unrestricted use, distribution and reproduction in any medium, provided the original author and source are credited.

Funding: No funding was received for this study.

Conflict of interest: The authors declare they have no conflicts of interest that are directly or indirectly related to the research.

\begin{abstract}
Background

To analyse the impact that the adoption of our institutional standard operating procedure (SOP) for cervical spine dislocations had on the timing of closed reduction at our hospital.

\section{Methods}

The study was a retrospective review of patients who presented to our institution with cervical dislocation injuries and who were managed with closed reduction. The patient records of acute cervical spine dislocations from 2015 to 2018, data from the Acute Spinal Cord Injury database along with patient's demographic information were gathered and compared. Participants within the study time frame were diagnosed with a cervical facet dislocation based on clinical examination findings and radiological confirmation. Patients who had reduction performed at other referring hospitals were excluded from the study.
\end{abstract}

\section{Results}

The practice within all tertiary hospitals in the Western Cape is to perform closed reduction of cervical fracture dislocations as soon as possible after injury. In this study the time between injury and closed reduction before introducing the SOP was $13 \mathrm{~h} 13 \mathrm{~min}$ and after introducing the SOP, the time increased to an average of $14 \mathrm{~h} 28 \mathrm{~min}$. The main cause of delay was the transfer time from the site of injury to the emergency ward. Other reasons for the delay include missed diagnosis, orthopaedic registrar unavailability and incomplete reduction bed.

\section{Conclusion}

This study found that the time taken for orthopaedic management of cervical dislocations increased by an hour after introduction of the SOP. Additionally, the overall time to reduction also increased. This was due to delays in transfer to the emergency ward and referral to Orthopaedics. We recommend that, in our setting, reduction could be initiated within an hour of patient arrival, if emergency ward doctors rapidly identified the problem and commenced cervical traction when the orthopaedic team was not immediately available. Our impression was that there was poor adherence to the new SOP guidelines on time management by the trauma team, and possibly transport delays prior to hospital admission. A further study to investigate the bottlenecks of the referral system is advisable.

Level of evidence: Level 4

Keywords: acute outcomes, cervical spine, dislocation injuries 


\section{Introduction}

Cervical dislocations are acute, high-risk injuries associated with a range of potentially catastrophic long-term disabilities. Regional hospital data has shown that up to $60 \%$ of spinal trauma, which accounts for $3-6 \%$ of all trauma admissions, involve injury to the cervical region. ${ }^{1}$ The most common mechanism of injury results from motor vehicle accidents (MVAs), violent assault or falls, with the typical patient being a male under the age of 30 years. ${ }^{2,3}$

These injuries have the potential to cause a profound change in lifestyle, with the resulting neurological deficit affecting the motor, sensory and autonomic nervous system. ${ }^{4}$ Patients require lifelong supportive care, impacting patients' quality of life, independence and psychological wellbeing. 5,6 Additionally, given the aetiology of the injury, a large proportion of those affected are earning an income with dependants reliant on them. As such, cervical spine injuries tend to have a profound effect on not only the individual patient but also on their direct family members and society.

Unless there are any contraindications, the best management for patients with cervical dislocations is early reduction, with skeletal traction to realign the vertebrae. ${ }^{7}$ The objective of early reduction is to align the vertebral column and alleviate external pressure on the spinal cord. Successful early reduction may potentially reduce subsequent neurological deficits. ${ }^{7} \mathrm{~A}$ key variable in this treatment method was found to be the time between the offending injury and the intervention being performed. ${ }^{8} \mathrm{~A}$ retrospective review of rugby players with cervical dislocations found a $63 \%$ difference in reported neurological improvement if closed reduction was performed within four hours of the injury - a larger quantified effect on patient recovery than surgical intervention. ${ }^{9}$

All Western Cape hospitals strive to perform closed reduction of cervical dislocations within four hours of the injury, ${ }^{10}$ partly to comply with a 2015 Constitutional Court ruling but also to adhere to best medical practice. ${ }^{11}$ This is, however, particularly challenging as the mean transport time between sustaining a spinal injury and receiving medical care was previously found to be three hours, which leaves little room to comply with the four-hour ruling..$^{10}$ Therefore, a new management protocol was introduced in June 2016 - the 'early reduction protocol' - requiring all closed reductions to be performed within one hour of admission.

This study aims to assess adherence and the effect of the 'early reduction SOP or protocol' on the timing of the reduction of cervical dislocations and its influence on the neurological outcomes of patients managed at our institution during the time period of the study.

\section{Materials and methods}

This was a retrospective analysis of records for patients managed at our institution from 2015 to 2018 . The study compared the management of patients with low and high velocity injuries treated before the introduction of the early reduction standard operating procedure (SOP) in June 2016 against those treated after. Low velocity injuries were classified as injuries sustained during sport activities or falls from a low height where the patients sustain purely ligamentous dislocation. High velocity injuries were classified as MVA and violent assaults where the patients sustain fracture dislocations. From the Acute Spinal Cord Injury database, records and notes of patients who presented to our institution from 2015 to 2018 with acute cervical dislocation and received subsequent closed reduction management were reviewed by the principal author (the researcher). The SOP requirement for cervical reduction was set to be within one hour after patients arriving at the primary emergency ward (ER). Variables such as the American Spinal Injury Association (ASIA) score, time to reduction, duration of hospital stay, along with patient mortality and morbidity, were retrieved. Data collected included age, sex, date, mechanism of injury, neurological examination findings and radiological diagnoses. A qualitative interview was conducted with the emergency room personnel at Groote Schuur Hospital (GSH) to complement our quantitative analysis findings.

Patients who presented to our institution in a conscious state with cervical injuries within the given time frame of the study and were diagnosed with a cervical facet dislocation based on clinical examination findings with radiological confirmation (X-rays or CT scan) were included in the study. All patients who were managed outside our institution with closed reduction were excluded from the study as were patients with other injuries such as open head injuries, an obtunded state or decreased level of consciousness.

\section{Qualitative assessment}

The qualitative assessment was conducted by the principal author between August and September 2018 on emergency personnel (ER nurses, ER doctors and orthopaedic registrars) at GSH. The participants were individually interviewed in person and asked to complete the 'yes/no' answers in Table / based on their area of speciality.

\section{Statistical analysis}

Data was summarised using descriptive statistics. Continuous variables were summarised using means and standard deviations, whereas categorical or nominal variables were summarised using percentages. Matched t-tests were used to test for significance between continuous variables, while chi-squared tests were used for categorical or nominal variables. Graphical analysis was used to display the distribution of variable(s) and to illustrate findings visually.

\section{Results}

The study comprised 19 participants, of whom $79 \%$ were male and $21 \%$ female. The median (IQR) age of participants was 48 years (26.0-55.0); range from 20 to 80 years (Figure 1). There was a pre-hospital delay between injury and arrival at the primary emergency ward (ER) of seven hours. The mean time between injury and closed reduction before introducing the new SOP was $13 \mathrm{~h} 13 \mathrm{~min}$ (Table II). After introducing the new SOP, the time to

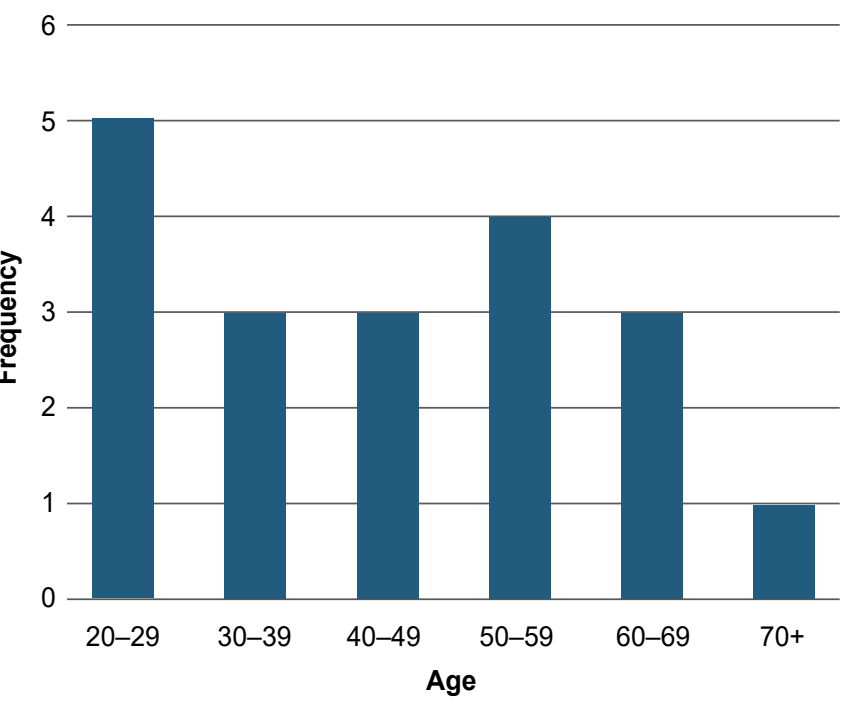

Figure 1. Distribution of patients' age (in years) in the study 
Table I: The qualitative assessment questionnaire tailored to area of specialty

\begin{tabular}{|c|c|c|c|}
\hline Questions & ER nurses & ER doctors & Orthopaedic registrars \\
\hline 1. Are you aware of the SOP for rapid reduction? & Yes/No & Yes/No & Yes/No \\
\hline 2. What is the four-hour rule under the Constitutional Court? & Yes/No & Yes/No & Yes/No \\
\hline 3. Do you know where the reduction bed and equipment are kept? & Yes/No & Yes/No & Yes/No \\
\hline 4. What patients require urgent neck $X$-rays? & Yes/No & Yes/No & N/A \\
\hline 5. Which doctors can apply cervical traction in an emergency? & Yes/No & Yes/No & N/A \\
\hline 6. Do you know who to refer to for neck dislocations? & N/A & Yes/No & N/A \\
\hline 7. With a cervical dislocation, do you request an MRI scan? & N/A & Yes/No & N/A \\
\hline 8. Is there always available radiography for rapid reductions? & $\mathrm{N} / \mathrm{A}$ & N/A & Yes/No \\
\hline 9. List causes that delay initiating reductions. & N/A & N/A & Yes/No \\
\hline $\begin{array}{l}\text { 10. If you are scrubbed in theatre and are referred a cervical } \\
\text { dislocation, what action do you take? }\end{array}$ & N/A & N/A & Yes/No \\
\hline
\end{tabular}

Table II: Time delays summary

\begin{tabular}{|c|c|c|c|c|c|c|c|c|c|}
\hline \multicolumn{3}{|c|}{$\begin{array}{c}\text { Period } \\
\text { (time in hours:minutes) }\end{array}$} & Injury to ER & $\begin{array}{l}\text { ER to ortho } \\
\text { referral }\end{array}$ & $\begin{array}{l}\text { Ortho referral } \\
\text { to assessment }\end{array}$ & $\begin{array}{l}\text { Ortho time } \\
\text { to start }\end{array}$ & $\begin{array}{l}\text { Ortho time } \\
\text { to complete }\end{array}$ & $\begin{array}{l}\text { Injury to } \\
\text { reduction }\end{array}$ & p-value \\
\hline \multirow{6}{*}{$\begin{array}{l}\text { Before } \\
\text { new SOP }\end{array}$} & \multicolumn{2}{|l|}{ Mean $(n=8)$} & $7: 45 \pm 8: 33$ & $1: 56 \pm 1: 14$ & $1: 08 \pm 0: 41$ & $1: 21 \pm 0: 44$ & $1: 01 \pm 0: 17$ & $13: 13 \pm 9: 07$ & \multirow{12}{*}{$<0.0001$} \\
\hline & \multicolumn{2}{|c|}{ Median $(n=8)$} & 03:17 & 01:40 & $00: 57$ & 01:07 & $00: 54$ & 09:19 & \\
\hline & \multicolumn{2}{|l|}{ Minimum } & 01:14 & $00: 34$ & 00:05 & $00: 25$ & $00: 45$ & 04:00 & \\
\hline & \multicolumn{2}{|l|}{ Maximum } & $24: 00$ & 04:00 & 02:00 & $02: 44$ & 01:30 & 05:30 & \\
\hline & \multirow[t]{2}{*}{ Percentiles } & 25 & 01:30 & $00: 51$ & $00: 40$ & 01:00 & 00:46 & 06:50 & \\
\hline & & 75 & $15: 13$ & $02: 57$ & 01:55 & 01:57 & 01:15 & $21: 56$ & \\
\hline \multirow{6}{*}{$\begin{array}{l}\text { After } \\
\text { new SOP }\end{array}$} & \multicolumn{2}{|l|}{ Mean $(n=11)$} & $07: 43 \pm 04: 39$ & $02: 50 \pm 03: 24$ & $01: 14 \pm 01: 10$ & $01: 51 \pm 02: 48$ & $00: 47 \pm 00: 34$ & $14: 28 \pm 08: 53$ & \\
\hline & \multicolumn{2}{|c|}{ Median $(n=11)$} & $08: 30$ & 01:36 & 01:00 & $00: 30$ & $00: 36$ & $13: 15$ & \\
\hline & \multicolumn{2}{|l|}{ Minimum } & 02:00 & 00:19 & $00: 15$ & $00: 15$ & 00:19 & 03:30 & \\
\hline & \multicolumn{2}{|l|}{ Maximum } & 13:56 & $10: 15$ & 04:19 & 09:00 & $02: 20$ & $07: 15$ & \\
\hline & \multirow[t]{2}{*}{ Percentiles } & 25 & 02:19 & $00: 20$ & $00: 30$ & $00: 15$ & $00: 30$ & 04:35 & \\
\hline & & 75 & $12: 06$ & $04: 25$ & 01:04 & 03:05 & 00:45 & $22: 25$ & \\
\hline
\end{tabular}

Table III: Comparison of admission versus discharge for post-reduction clinical measurements

\begin{tabular}{|c|c|c|c|c|c|c|}
\hline \multicolumn{7}{|c|}{ Paired t-test (two-tailed) } \\
\hline & & Mean & $\mathbf{n}$ & Std deviation & Std error mean & p-value \\
\hline \multirow[t]{2}{*}{ Pair 1} & Pre-reduction ASIA scale & 2.1 & 19 & 1.6 & 0.4 & \multirow[t]{2}{*}{0.331} \\
\hline & Post-reduction ASIA scale & 2.2 & 19 & 1.6 & 0.4 & \\
\hline \multirow[t]{2}{*}{ Pair 2} & Admission ASIA motor score & 25.1 & 19 & 32.5 & 7.5 & \multirow[t]{2}{*}{0.078} \\
\hline & Discharge ASIA motor score & 29.7 & 19 & 36.9 & 8.5 & \\
\hline \multirow[t]{2}{*}{ Pair 3} & Admission ASIA light touch & 39.5 & 19 & 40.6 & 9.3 & \multirow[t]{2}{*}{0.454} \\
\hline & Discharge ASIA light touch & 42.0 & 19 & 44.2 & 10.2 & \\
\hline \multirow[t]{2}{*}{ Pair 4} & Admission ASIA pinprick & 40.5 & 19 & 40.2 & 9.2 & \multirow[t]{2}{*}{0.662} \\
\hline & Discharge ASIA pinprick & 41.8 & 19 & 44.3 & 10.2 & \\
\hline
\end{tabular}

closed reduction increased significantly $(p<0.0001)$ to a mean of 14 h 28 min (Table II).

Other associated injuries were cervical fractures $(63.1 \%)$ and pelvic fractures in $26 \%$. Furthermore, most common cervical fractures were bilateral lamina fractures in $21 \%$ and vertebral body fractures in $11 \%$ (Figures $2 a$ and $2 b$ ).

The main time delays (Figure 3) were between injury and arrival at the ER (7 h 43 min after the new SOP). There was minimal change between pre- and post-introduction of the new SOP, with only a $6 \%$ decrease in time taken between injury and arrival at the ER.

A matched t-test was used to compare pre- and post-mean changes on the ASIA scale, pre-reduction and post-reduction
(Table III), and no significant changes were found (pre- versus post$p=0.331$ ). Similarly, there were no significant changes between admission versus discharge for: ASIA motor score, $p=0.078$; ASIA light touch, $p=0.454$; ASIA pinprick, $p=0.662$.

Table IV presents the time delays in the referral system at GSH. The median time delay from injury to the ER was increased by $55 \%$ ( $07 \mathrm{~h} 13 \mathrm{~min}$ ), whereas the median time from the ER to the orthopaedic registrar on call was increased by $12 \%$ ( $01 \mathrm{~h} 36 \mathrm{~min}$ ). Times from start to completion of reduction by the orthopaedic registrar were increased by a median of $8 \%$ ( $01 \mathrm{~h} 00 \mathrm{~min}$ ) and $6 \%$ (00 h $45 \mathrm{~min}$ ), respectively.

In this study, there were equal rates of reduction success before the new SOP and after the new SOP ( $p=50 \%)$ (Figure 4). 


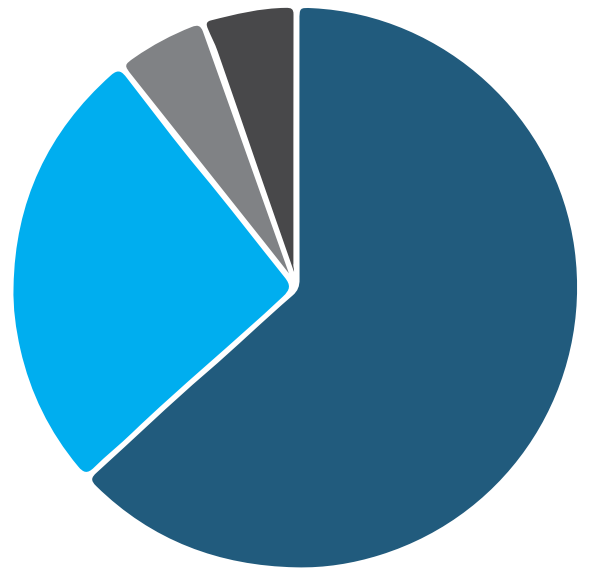

Cervical injuries (63\%)

Pelvic fracture $(26 \%)$

AKI/HTN (5\%)

Nil (5\%)

Figure 2a. Injuries and medical conditions sustained by patients in the study

The common injuries were sustained from MVAs (37\%) and falling (37\%). The most common pattern of injury was C5/C6 bifacet dislocation (32\%). Common neurological deficits were C4 motor complete sensory complete (MCSC) (26\%) and C5 MCSC (21\%). Most patients had a pre-reduction ASIA-A, 63\% and the most common post-reduction score was ASIA A, 63\% (Table V).

\section{Qualitative findings}

Additional in-depth qualitative interviews were used to complement evidence gathered quantitatively. Table VI summarises themes that emerged from in-depth interviews with five ER nurses, five ER doctors and five orthopaedic registrars. The red colour coding highlights answers indicating poor understanding of the

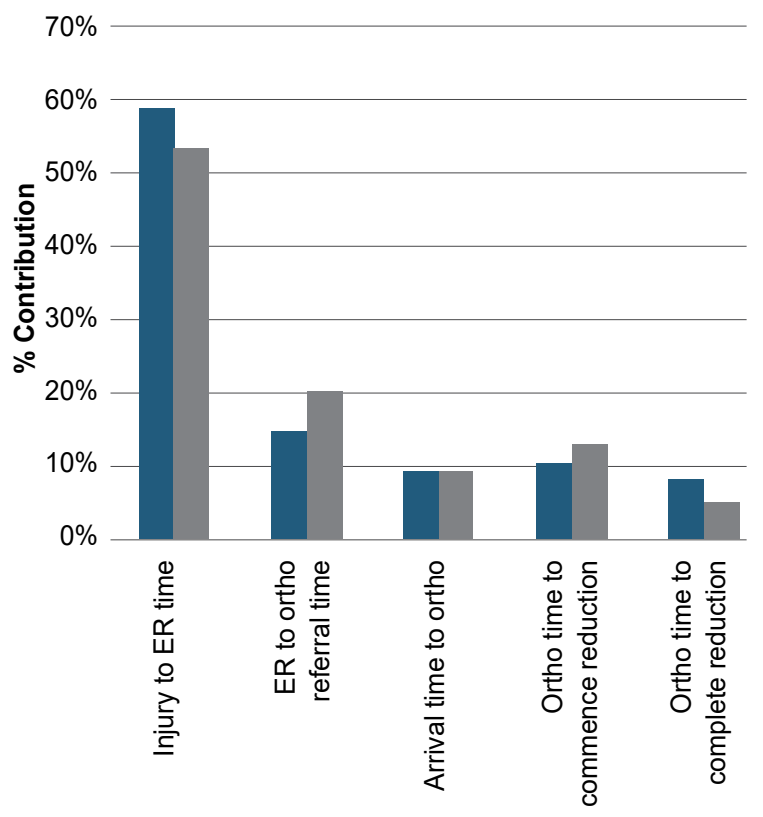

Delay points

Figure 3. Change in time delays in the emergency referral system, before and after new SOPs

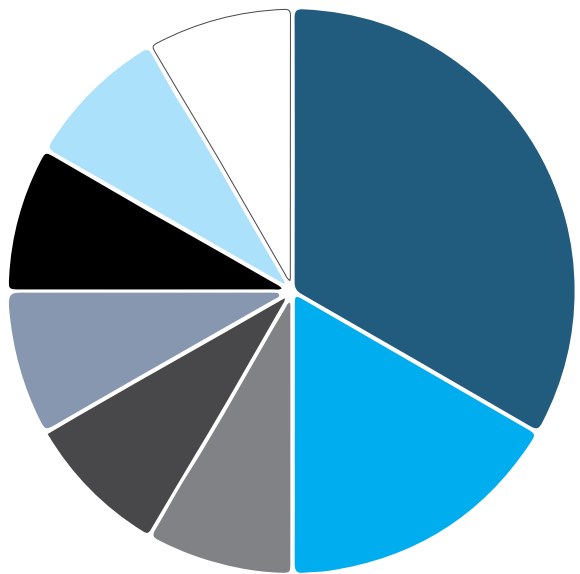

Bilateral C4 lamina fracture (21\%)

C6 body fracture (11\%)

C6 spinous process fracture $(5 \%)$

- C5 transverse process fracture (5\%)

C7 superior facet fracture $(5 \%)$

C5 body burst fracture spinal stenosis (5\%)

Right facet fracture, C6 compression fracture (5\%)

$\square$ Chip fracture left interior facet (5\%)

Figure 2b. Cervical Injuries sustained by patients in the study

management of cervical dislocations while answers in green demonstrate a better knowledge of cervical dislocation management. There was no awareness of the SOP for rapid reduction among ER nurses $0 \%(n=5)$ and ER doctors $0 \%(n=5)$; the exception was the orthopaedic registrars who had $100 \%(n=5)$ level of awareness. In addition, orthopaedic registrars had $100 \%(n=5)$ level of awareness on the 'four-hour ruling under the Constitutional Court', while ER nurses had 0\% $(n=5)$ and ER doctors had $20 \%$ $(n=1)$. Only two out five (40\%) ER nurses knew 'where the reduction bed and equipment were kept'; this shows a knowledge gap since ER nurses attend most cases during admissions. Surprisingly, only one out of five (20\%) orthopaedic registrars 'knew where the reduction bed and equipment are kept'.

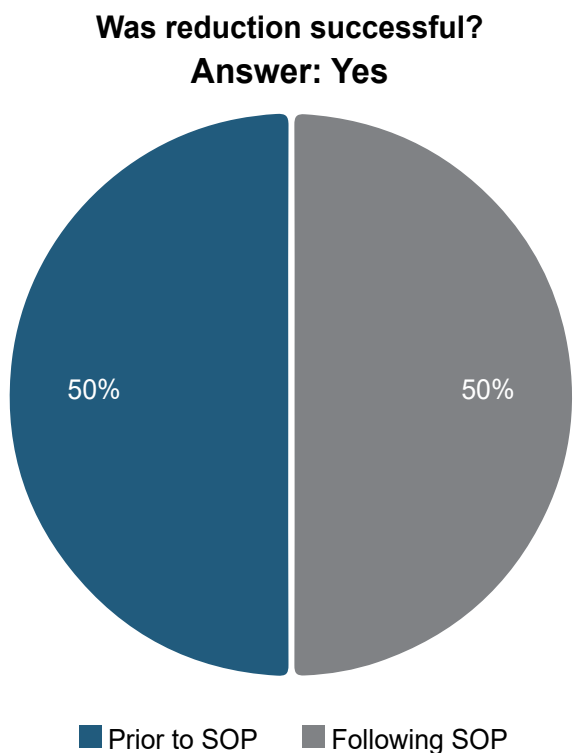

Figure 4: Percentage of successful reduction pre- and post-introduction of the SOP 
Table IV: Time delays in the referral system post-SOP

\begin{tabular}{|c|c|c|c|c|c|c|c|}
\hline & Injury to ER & $\begin{array}{l}\text { ER to ortho } \\
\text { referral }\end{array}$ & $\begin{array}{l}\text { Ortho referral } \\
\text { to assessment }\end{array}$ & $\begin{array}{l}\text { Ortho time to } \\
\text { start reduction }\end{array}$ & $\begin{array}{l}\text { Ortho time to } \\
\text { complete reduction }\end{array}$ & $\begin{array}{l}\text { Injury to reduction } \\
\text { total time }\end{array}$ \\
\hline \multicolumn{2}{|c|}{ Mean (hours:minutes) } & $07: 44(56 \%)$ & $02: 27(18 \%)$ & 01:11 (8\%) & $01: 39(12 \%)$ & $00: 53(6 \%)$ & $13: 56(100 \%)$ \\
\hline \multicolumn{2}{|c|}{ Median (hours:minutes) } & $07: 13(55 \%)$ & $01: 36(12 \%)$ & 01:00 (8\%) & $01: 00(8 \%)$ & $00: 45(6 \%)$ & $13: 05(100 \%)$ \\
\hline \multicolumn{2}{|l|}{ Std deviation } & $06: 21$ & $02: 41$ & $00: 58$ & 02:09 & $00: 28$ & $08: 45$ \\
\hline \multicolumn{2}{|l|}{ Minimum } & 01:14 & 00:19 & 00:05 & $00: 15$ & 00:19 & 03:30 \\
\hline \multicolumn{2}{|l|}{ Maximum } & 00:00 & $10: 15$ & $04: 19$ & 09:00 & $02: 20$ & $07: 15$ \\
\hline \multirow[t]{2}{*}{ Percentiles } & 25 & 02:00 & $00: 34$ & $00: 40$ & $00: 25$ & $00: 34$ & $06: 45$ \\
\hline & 75 & $12: 06$ & 03:00 & $01: 43$ & $02: 10$ & $01: 15$ & $22: 25$ \\
\hline
\end{tabular}

Table V: Common description of patient notes

\begin{tabular}{|c|c|c|c|}
\hline Variable & Categories & Frequencies & $(\%)$ \\
\hline \multirow[t]{7}{*}{ Cause of injury } & Assault & 1 & 5 \\
\hline & Diving accident & 1 & 5 \\
\hline & Falling & 7 & 37 \\
\hline & MVA & 7 & 37 \\
\hline & PVA & 1 & 5 \\
\hline & Surfing accident & 1 & 5 \\
\hline & Train accident & 1 & 5 \\
\hline \multirow[t]{9}{*}{ Cervical level } & C4/5BFD & 1 & 5 \\
\hline & C4/5UFD & 1 & 5 \\
\hline & C4/C5BFD & 3 & 16 \\
\hline & C4/C5UFD & 1 & 5 \\
\hline & C5/C6BFD & 6 & 32 \\
\hline & C5/C6UFD & 2 & 11 \\
\hline & C6/7UFD & 1 & 5 \\
\hline & C6/C7BFD & 2 & 11 \\
\hline & C6/C7UFD & 2 & 11 \\
\hline \multirow{9}{*}{$\begin{array}{l}\text { Neurological } \\
\text { deficit }\end{array}$} & C3-4MISI & 1 & 5 \\
\hline & C3-5MCsC & 1 & 5 \\
\hline & C4-C5MCSC & 2 & 11 \\
\hline & C4MCSC & 5 & 26 \\
\hline & C4MISI & 1 & 5 \\
\hline & C5MCSC & 4 & 21 \\
\hline & C5MCSI & 1 & 5 \\
\hline & C5MISI & 2 & 11 \\
\hline & Nil & 2 & 11 \\
\hline \multirow{11}{*}{$\begin{array}{l}\text { Other injury } \\
\text { or medical } \\
\text { conditions }\end{array}$} & AKI, hypertension & 1 & 5 \\
\hline & Bilateral C4 lamina fracture & 4 & 21 \\
\hline & $\begin{array}{l}\text { C } 5 \text { body burst fracture } \\
\text { spinal stenosis }\end{array}$ & 1 & 5 \\
\hline & $\begin{array}{l}\text { C5 transverse process } \\
\text { fracture }\end{array}$ & 1 & 5 \\
\hline & C6 body fracture & 2 & 11 \\
\hline & C6 spinous process fracture & 1 & 5 \\
\hline & Nil & 1 & 5 \\
\hline & $\begin{array}{l}\text { Rt facet fracture,C6 } \\
\text { compare fracture }\end{array}$ & 1 & 5 \\
\hline & $\begin{array}{l}\text { Scapula and pelvic fracture } \\
\text { C7 superior facet fracture } \\
\text { C7 transverse process }\end{array}$ & 1 & 5 \\
\hline & $\begin{array}{l}\text { Chip fracture left inferior } \\
\text { facet }\end{array}$ & 1 & 5 \\
\hline & Pelvic fracture & 5 & 26 \\
\hline
\end{tabular}

\begin{tabular}{|l|c|c|c|}
\hline \begin{tabular}{l} 
Table V: Continued \\
\multicolumn{1}{|c|}{ Variable }
\end{tabular} & Categories & Frequencies & (\%) \\
\hline $\begin{array}{l}\text { Pre-reduction } \\
\text { ASIA scale }\end{array}$ & A & 12 & 63 \\
\hline & B & 1 & 5 \\
\hline & C & 1 & 5 \\
\hline & D & 2 & 11 \\
\hline Post-reduction & E & 3 & 16 \\
\hline ASIA scale & A & 12 & 63 \\
\hline & C & 2 & 11 \\
\hline & D & 2 & 11 \\
\hline EKI: & E & 3 & 16 \\
\hline
\end{tabular}

AKI: acute kidney injury; ASIA scale: American Spinal Injury Association scale BFD: bifacet dislocation; MCSC: motor complete sensory complete; MISI: motor incomplete sensory incomplete; MVA: motor vehicle accident; PVA: pedestrian vehicle accident; UFD: unifacet dislocation

\section{Discussion}

Cervical dislocations are serious injuries associated with a range of potentially catastrophic long-term disabilities. Previous regional hospital data has shown that up to $60 \%$ of spinal trauma, which accounts for $3-6 \%$ of all trauma admissions, is caused by injury to the cervical region. ${ }^{1}$ The most common mechanism of injury is the result of an MVA, violent assault or fall - with the typical patient being a male under the age of 30 years. ${ }^{2,3}$ In this study MVA and falls were the most common causes of injury: MVA $37 \%$ and falls $37 \%$.

Previously, it had been recommended that the time between injury and closed reduction should be within four hours in order to have favourable neurological outcomes. ${ }^{9,12}$ In this study, the mean time between injury and closed reduction before introducing the new SOP was $13 \mathrm{~h} 13 \mathrm{~min}$, with median time of $9 \mathrm{~h} 19 \mathrm{~min}$. After introducing the new SOP, the mean time significantly increased to $14 \mathrm{~h} 28 \mathrm{~min}$ and median time of $13 \mathrm{~h} 15 \mathrm{~min}$. Based on the study findings, the intended potential benefits of the SOP were not achieved. There was no significant improvement in reduction times from initial injury. The main delay was from injury to arrival at the ER. In-depth study reflected the challenges of low awareness of the SOP for rapid reduction; lack of knowledge of where the reduction bed and equipment are kept; and inconsistency on preparations before surgery. Reduction beds and equipment might not be maintained and not always prepared, all of which point to low availability of adequate resources. These gaps explain why there was no significant improvement on several continuous outcomes and increased time delays along the referral chain before actual reduction. It took $1 \mathrm{~h} 21 \mathrm{~min}$ to $1 \mathrm{~h} 51 \mathrm{~min}$ from assessment to initiating reduction, with a variety of factors causing delays including doctors needing to look for equipment. The SOP failed to improve on this time to initiate reduction. Although recent 
Table VI: In-depth interviews with ER nurses, ER doctors and orthopaedic registrars

\begin{tabular}{|c|c|c|c|c|c|c|}
\hline ER nurses & $\begin{array}{l}\text { 1. Are you aware of } \\
\text { the SOP for rapid } \\
\text { reduction? }\end{array}$ & $\begin{array}{l}\text { 2. What is the } \\
\text { four-hour rule under } \\
\text { the Constitutional } \\
\text { Court? }\end{array}$ & $\begin{array}{l}\text { 3. Do you know } \\
\text { where the } \\
\text { reduction bed and } \\
\text { equipment are } \\
\text { kept? }\end{array}$ & $\begin{array}{l}\text { 4. What patients } \\
\text { require urgent neck } \\
\text { X-rays? }\end{array}$ & $\begin{array}{l}\text { 5. Which } \\
\text { doctors can } \\
\text { apply cervical } \\
\text { traction in an } \\
\text { emergency? }\end{array}$ & \\
\hline 1 & No, I'm not aware & $\begin{array}{l}\text { Observation of a } \\
\text { patient }\end{array}$ & Yes & $\begin{array}{l}\text { Patient with long } \\
\text { bone fracture, poly } \\
\text { trauma patient }\end{array}$ & Neurosurgeon & \\
\hline 2 & No, I'm not aware & I don't know & No & $\begin{array}{l}\text { Spine injury, MVA, } \\
\text { neck pain, fall from } \\
\text { height }\end{array}$ & I don't know & \\
\hline 3 & No, I'm not aware & I don't know & Yes & $\begin{array}{l}\text { Neck pain, fall from } \\
\text { height, MVA }\end{array}$ & $\begin{array}{l}\text { Orthopaedic } \\
\text { doctor }\end{array}$ & \\
\hline 4 & No, I'm not aware & I don't know & No & $\begin{array}{l}\text { MVA, fall from height, } \\
\text { gunshot, knife stab }\end{array}$ & $\begin{array}{l}\text { Orthopaedic } \\
\text { doctor, } \\
\text { neurosurgeon }\end{array}$ & \\
\hline 5 & No, I'm not aware & I don't know & Yes & Neck pain & $\begin{array}{l}\text { Orthopaedic } \\
\text { doctor, ASCl }\end{array}$ & \\
\hline ER doctors & $\begin{array}{l}\text { 1. Are you aware of } \\
\text { the SOP for rapid } \\
\text { reduction? }\end{array}$ & $\begin{array}{l}\text { 2. What is the } \\
\text { four-hour rule under } \\
\text { the Constitutional } \\
\text { Court? }\end{array}$ & $\begin{array}{l}\text { 3. Do you know } \\
\text { where the } \\
\text { reduction bed and } \\
\text { equipment are } \\
\text { kept? }\end{array}$ & $\begin{array}{l}\text { 4. What patients } \\
\text { require urgent neck } \\
\text { X-rays? }\end{array}$ & $\begin{array}{l}\text { 5. Which } \\
\text { doctors can } \\
\text { apply cervical } \\
\text { traction in an } \\
\text { emergency? }\end{array}$ & $\begin{array}{l}\text { 6. Do you know } \\
\text { who to refer to for } \\
\text { neck dislocations? }\end{array}$ \\
\hline 1 & No & Not sure & Yes & $\begin{array}{l}\text { MVA, fall from height, } \\
\text { neck pain }\end{array}$ & $\begin{array}{l}\text { Orthopaedic, } \\
\text { neurosurgeon, } \\
\text { ASCl }\end{array}$ & Orthopaedic, ASCI \\
\hline 2 & No & Not sure & Yes & $\begin{array}{l}\text { Fall from height, } \\
\text { MVA, gunshot, knife } \\
\text { stab }\end{array}$ & Orthopaedic & $\begin{array}{l}\text { Orthopaedic, } \\
\text { neurosurgeon, } \\
\mathrm{ASCl}\end{array}$ \\
\hline 3 & No & Not sure & Yes & $\begin{array}{l}\text { Fall from height, } \\
\text { MVA, gunshot, knife } \\
\text { stab }\end{array}$ & $\begin{array}{l}\text { Orthopaedic, } \\
\mathrm{ASCl} \\
\text { neurosurgeon }\end{array}$ & $\begin{array}{l}\text { Orthopaedic, } \\
\text { neurosurgeon }\end{array}$ \\
\hline 4 & No & Not sure & Yes & $\begin{array}{l}\text { Neck pain, significant } \\
\text { tenderness, } \\
\text { neurological fallout }\end{array}$ & Orthopaedic & Orthopaedic on call \\
\hline 5 & No & $\begin{array}{l}\text { Neck dislocation } \\
\text { should be reduced } \\
\text { within four hours }\end{array}$ & Yes & $\begin{array}{l}\text { Low GCS, suspected } \\
\text { C-spine injury, focal } \\
\text { neurological deficit in } \\
\text { polytrauma }\end{array}$ & Orthopaedic & Orthopaedic on call \\
\hline $\begin{array}{l}\text { Orthopaedic } \\
\text { registrars }\end{array}$ & $\begin{array}{l}\text { 1. Are you aware of } \\
\text { the SOP for rapid } \\
\text { reduction? }\end{array}$ & $\begin{array}{l}\text { 2. What is the } \\
\text { four-hour rule under } \\
\text { the Constitutional } \\
\text { Court? }\end{array}$ & $\begin{array}{l}\text { 3. Are the reduction } \\
\text { bed and equipment } \\
\text { maintained and } \\
\text { always prepared? }\end{array}$ & $\begin{array}{l}\text { 4. Is there } \\
\text { always available } \\
\text { radiographer for } \\
\text { rapid reduction? }\end{array}$ & $\begin{array}{l}\text { 5.List causes } \\
\text { that delay } \\
\text { initiating } \\
\text { reduction? }\end{array}$ & $\begin{array}{l}\text { 6. If you are } \\
\text { scrubbed in } \\
\text { theatre and are } \\
\text { referred a cervical } \\
\text { reduction, what do } \\
\text { you do? }\end{array}$ \\
\hline 1 & Yes & $\begin{array}{l}\text { C-spine dislocation } \\
\text { must be reduced in } \\
\text { four hours }\end{array}$ & Not always & Yes & $\begin{array}{l}\text { Late referral, late } \\
\text { presentation }\end{array}$ & $\begin{array}{l}\text { Will ask someone } \\
\text { on call to do it }\end{array}$ \\
\hline 2 & Yes & $\begin{array}{l}\text { C-spine dislocation } \\
\text { must be reduced in } \\
\text { four hours }\end{array}$ & Not always & Yes & $\begin{array}{l}\text { Late referral, late } \\
\text { presentation }\end{array}$ & $\begin{array}{l}\text { Will ask the senior } \\
\text { trauma doctor to } \\
\text { do it }\end{array}$ \\
\hline 3 & Yes & $\begin{array}{l}\text { C-spine dislocation } \\
\text { must be reduced in } \\
\text { four hours }\end{array}$ & Yes & Yes & $\begin{array}{l}\text { Late referral, late } \\
\text { presentation }\end{array}$ & $\begin{array}{l}\text { Will ask someone } \\
\text { on call }\end{array}$ \\
\hline 4 & Yes & $\begin{array}{l}\text { C-spine dislocation } \\
\text { must be reduced in } \\
\text { four hours }\end{array}$ & Not always & Yes & $\begin{array}{l}\text { Late referral, late } \\
\text { presentation }\end{array}$ & $\begin{array}{l}\text { Will ask to call } \\
\text { consultant }\end{array}$ \\
\hline 5 & Yes & $\begin{array}{l}\text { C-spine dislocation } \\
\text { must be reduced in } \\
\text { four hours }\end{array}$ & Not always & Yes & $\begin{array}{l}\text { Late referral, late } \\
\text { presentation }\end{array}$ & $\begin{array}{l}\text { Ask someone in } \\
\text { trauma to reduce it }\end{array}$ \\
\hline
\end{tabular}


data showed that the average transport time between sustaining a spinal injury and receiving medical care was three hours, in this study the average time was $13 \mathrm{~h} 56$ min after a new management protocol was introduced as of June 2016 whereby all closed reductions should be performed within one hour of admission. This indicates a discrepancy in terms of policy availability and/or SOP adherence and implementation of guidelines regarding this issue.

The SOP was an effort to improve reduction times; however, our review found that the overall time from injury to reduction had not appreciably improved. Furthermore, the time taken for ER doctors to assess the patient and refer to Orthopaedics had increased from $1 \mathrm{~h} 56 \mathrm{~min}$ to $2 \mathrm{~h} 56 \mathrm{~min}$. The possible reasons for this were difficulties in locating required equipment, lack of equipment, policy unavailability and very low SOP adherence. We recommend that, in our setting, reduction could be done within an hour of patient arrival if other ER doctors activate the early reduction protocol, even in the absence of an orthopaedic registrar. Furthermore, we recommend pre-hospital diagnosis by paramedics be done at the scene of the accident and in-hospital activation of the SOP by the ER staff which would then result in time-saving.

In the qualitative assessment of staff, results showed only orthopaedic doctors were aware of the new SOP for cervical dislocation injuries and had knowledge of the four-hour constitutional rule for performing early reduction of cervical dislocation injuries. Based on these findings, we recommend that all ER staff must be educated and made aware of the SOP and the four-hour rule. The SOP should be available on large posters in the ER.

Limitations of the study are that the new SOP did not include the transport time (it addresses the time from arrival in the ER to reduction). Secondly, most of the study patients had high energy mechanisms of injury thus other associated injuries resulted in their exclusion from having acute reduction performed. Thirdly, due to the retrospective aspect of the study, selection bias and misclassification or information bias might have been introduced.

\section{Conclusion}

In this study, motor vehicle accidents and falls were the most common causes of injury. The time taken from the site of injury to an assessment and complete reduction was significantly increased after introduction of the new SOP. There were no significant changes in ASIA scales post-introduction of the new SOP. The main message is that there is very poor adherence to the new SOP guidelines on time management along the emergency health referral system by healthcare workers (nurses and general doctors). Future study is needed to examine the role of patient assessment at a primary care level prior to transfer to a tertiary hospital for patients with suspected spinal injury.

\section{Ethics statement}

This study was approved by the University of Cape Town Human Ethics Committee (2018/137). Verbal consent was obtained from doctors and nurses that participated in the study. There was no direct involvement of patients, thus no need for verbal or oral consent. The study comprised patient notes and records, with each patient identified by their hospital number only. All study data storage was password protected.

\section{Declaration}

The authors declare authorship of this article and that they have followed sound scientific research practice. This research is original and does not transgress plagiarism policies.

\section{Author contributions}

Ayik GDD: Primary author; study design, data collection, data analysis

Mukabeta TDM: Data collection and analysis

Nyandoro G: Information technology and data analysis

Osborne C: Data collection and analysis

Kruger NA: Conceptualisation, study design, manuscript revision and supervision

\section{ORCID}

Ayik GDD https://orcid.org/0000-0002-4205-8820

Mukabeta TDM 19 https://orcid.org/0000-0002-6581-5660

Nyandoro G https://orcid.org/0000-0001-8991-0948

Osborne C https://orcid.org/0000-0003-1334-8156

Kruger NA https://orcid.org/0000-0002-8543-5745

\section{References}

1. Ghafoor A, Martin T, Gopalakrishnan S, Viswamitra S. Caring for the patients with cervical spine injuries: what have we learned? J Clin Anesth. 2005;17:640-49.

2. Joseph C, Delcarme A, Vlok I, et al. Incidence and aetiology of traumatic spinal cord injury in Cape Town, South Africa: a prospective, population-based study. Spinal Cord. 2015;53:692-96.

3. Sothmann J, Stander J, Kruger N, Dunn R. Epidemiology of acute spinal cord injuries in the Groote Schuur Hospital Acute Spinal Cord Injury (GSH ASCI) Unit, Cape Town, South Africa, over the past 11 years. S Afr Med J. 2015;105:835.

4. Savic $\mathrm{G}$, DeVivo $\mathrm{M}$, Frankel $\mathrm{H}$, et al. Long-term survival after traumatic spinal cord injury: a 70-year British study. Spinal Cord. 2017;55:651-58.

5. Malhotra M, Bhatoe B, Sudambrekar S. Spinal cord injuries. Med J Armed Forces India. 2010;66:325-28.

6. Oderud T. Surviving spinal cord injury in low-income countries. Afr J Disabil. 2014;3:1-9.

7. Gelb D, Hadley M, Aarabi B, et al. Initial closed reduction of cervical spinal fracture-dislocation injuries. J Neurosurg. 2013;72:73-83.

8. Storey R, Singhal R, Inglis $\mathrm{T}$, et al. Urgent closed reduction of the dislocated cervical spine in New Zealand. ANZ J Surg. 2017;88:56-61.

9. Newton D, England M, Doll H, Gardner B. The case for early treatment of dislocations of the cervical spine with cord involvement sustained playing rugby. Bone Joint J. 2011;93-B:1646-52.

10. Potgieter $\mathrm{M}$, Badenhorst $\mathrm{DH}$, Mohideen $\mathrm{M}$, et al. Closed traction reduction of cervical spine facet dislocations: Compelled by law. S Afr Med J. 2019;109:854-58.

11. Oppelt v Head: Health, Department of Health Provincial Administration: Western Cape (CCT185/14) [2015] ZACC 33; 2016 (1) SA 325 (CC); 2015 (12) BCLR 1471 (CC) (14 October 2015).

12. Storey RN, Singhal R, Ingli T. Urgent closed reduction of the dislocated cervical spine in New Zealand. ANZ J Surg. 2018;88:56-61. 